\title{
Propostas para minimizar os riscos de acidentes de trânsito envolvendo crianças e adolescentes
}

\author{
Proposals for controlling traffic accident risks \\ for children and adolescents
}

Eloir de Oliveira Faria 1

Marilita Gnecco de Camargo Braga 1

\footnotetext{
1 Coordenação dos Programas de Pós-graduação de Engenharia (COPPE), Programa de Engenharia de Transportes (PET), Centro de Tecnologia, Universidade Federal do Rio de Janeiro, Bloco H, Sala 106, Caixa Postal 68512, Cidade

Universitária, 21945-970 Rio de Janeiro, RJ, Brasil eloir@fst.com.brou eloir@pet.coppe.ufrj.br
}

\begin{abstract}
This paper analyses traffic safety problems concerning children and adolescents. It proposes a programme aimed at preventing traffic accidents, including measures related to urban aspects and to traffic education, engineering and enforcement. The programme proposed aims at preventing pedestrian accidents and includes a traffic accident data system, the checking of all pedestrian routes and main crossings, with special attention to traffic lights, traffic education actions, blackspot treatment, remedial measures directed to pavements, enforcement and rescue services with medical care for the injured. The analyses focusing on traffic education practice in Brazil have indicated that it will not promote changes in users' behaviour. Therefore, the article suggests the basis of a new approach.
\end{abstract}

Key words Traffic; Safety; Education; Child; Adolescent
Resumo Este texto analisa a situação de insegurança de crianças e adolescentes no trânsito e propõe um programa de ação para a prevenção de acidentes, com medidas de urbanismo, educação, engenharia e fiscalização de trânsito. Propõe um programa de prevenção de atropelamentos, que consiste na implantação de um sistema de informações sobre acidentes de trânsito, na verificação das rotas de circulação de pedestres e dos principais pontos de travessia, na revisão dos semáforos, no tratamento e na ação educativa junto às travessias de pedestres, no tratamento de pontos críticos, na melhoria dos passeios e na ampliação e melhoria da fiscalização do trânsito e do atendimento aos acidentados. A análise da prática brasileira na educação para o trânsito indicou que não é possível mudar comportamentos no trânsito abordando o tema como tem sido feito, portanto, as bases de uma nova proposta são esboçadas.

Palavras-chave Trânsito; Segurança; Educação; Criança; Adolescente 


\section{Introdução}

Os acidentes de trânsito se transformaram num dos problemas mais graves que a população brasileira enfrenta nos seus deslocamentos, diários ou não. Em 1997, 24.107 pessoas morreram e 324.838 ficaram feridas (Brasil, 1999a). Quanto às pessoas com menos de 15 anos, estas mesmas estatísticas oficiais revelaram que 2.483 morreram ( $10,3 \%$ do total) e 35.227 ficaram feridas (10,8\% do total). Estes números são alarmantes, tanto pela sua magnitude, quanto pelo fato de ser comum no Brasil o sub-registro de acidentes de trânsito (Braga, 1992).

Os objetivos básicos de um trabalho voltado para o aumento das condições de segurança do tráfego são: a) reduzir os números globais de acidentes, de mortos e de feridos; b) reduzir o risco presente nas vias; c) reduzir as conseqüências dos acidentes. Para cada um destes objetivos, pode-se ter um conjunto de medidas apropriadas, mas de caráter distinto. Por exemplo, para o primeiro grupo, pode-se lançar mão de medidas que façam com que os usuários abandonem os veículos particulares e passem a utilizar modos de transporte mais seguros, como o metrô, por exemplo (cerca de 95\% dos acidentes de transporte no Brasil ocorrem no modo rodoviário - Brasil, 1999b). Para o segundo grupo, o poder público pode direcionar seus esforços para uma ação fiscalizadora do trânsito, para a identificação e tratamento dos pontos críticos em áreas urbanas e para a educação para o trânsito. Para o último conjunto de objetivos, o incentivo ao uso de equipamentos como o cinto de segurança (no interior de veículos) e o capacete (para ciclistas e motociclistas), ou ainda o socorro aos acidentados são formas de diminuir a gravidade dos acidentes.

É preciso, portanto, conhecer o problema para definir o objetivo prioritário a alcançar e, a partir daí, escolher as medidas mais apropriadas para tratar do problema. É nestas bases que um trabalho em segurança de tráfego deveria se dar. Entretanto, para a imensa maioria das cidades brasileiras, esbarra-se no que deveria ser o ponto de partida: faltam informações que permitam descrever a situação de forma criteriosa e proceder a um diagnóstico que aponte as soluções mais recomendadas.

Deste modo, o panorama geral dos acidentes de trânsito no país, apontado anteriormente, fornece uma dimensão do problema (gra- ve!), mas os dados precários e as informações disponíveis não permitem uma descrição mais detalhada. Neste texto, procura-se analisar a segurança de crianças e adolescentes, com base nas informações limitadas que se dispõe e na experiência com relação à prevenção dos tipos de acidentes aos quais este grupo de usuários está mais sujeito.

No entanto, um trabalho de prevenção dos acidentes de trânsito deve necessariamente incluir uma reflexão sobre a evolução do problema e discutir medidas de aumento de segurança que não se restrinjam à abordagem da engenharia de tráfego (área de conhecimento responsável por garantir condições de fluidez e segurança ao tráfego de veículos e de pedestres). Assim, apresentam-se medidas que relacionam os conhecimentos da engenharia de tráfego, da educação e do urbanismo para uma reorganização do espaço urbano, que inclua também a prevenção de acidentes.

\section{Uma breve descrição do problema}

Apesar das dificuldades relacionadas aos dados disponíveis, será feita uma avaliação da extensão do problema no que diz respeito ao envolvimento de crianças e adolescentes em acidentes de trânsito, com base nas informações coletadas. A primeira dificuldade em descrever a situação é relativa à definição das faixas etárias que congregam cada um destes grupos. Segundo o Estatuto da Criança e do Adolescente (Brasil, 1993a), é considerada criança a pessoa até 12 anos de idade incompletos e adolescente, aquela com idade entre 12 e 18 anos. Entretanto, dados sobre mortalidade em crianças e adolescentes, compilados pela Secretaria Municipal de Saúde do Rio de Janeiro, pela Secretaria Estadual de Saúde do Rio de Janeiro e pelo Departamento Nacional de Trânsito (Denatran) fornecem estatísticas de acidentes segundo faixas etárias (de 0 a 4 anos, de 5 a 14 anos e de 15 a 19 anos ou de 15 a 24 anos) completamente distintas daquelas recomendadas pelo Estatuto da Criança e do Adolescente, dificultando ainda mais a possibilidade de comparações entre os dados.

As estatísticas oficiais do Denatran (Brasil, 1999a), sintetizadas nas Tabelas 1 e 2 foram compiladas a partir dos Boletins de Registro de Acidentes de Trânsito (Brat), preenchidos por agentes de trânsito no momento do acidente. É interessante ressaltar que, além 
Tabela 1

Vítimas fatais e não fatais em acidentes de trânsito no Brasil, nas áreas rural e urbana, para o ano de 1997 (Brasil, 1999a)

\begin{tabular}{lcrrrc}
\hline Faixa etária & \multicolumn{2}{c}{ Vítimas fatais } & \multicolumn{2}{c}{ Vítimas não fatais } & \multicolumn{2}{c}{ Letalidade } \\
& \multicolumn{1}{c}{$\mathrm{n}$} & \multicolumn{1}{c}{$\%$} & $\mathrm{n}$ & $\%$ & $\%$ \\
\hline 0 a 4 anos & 591 & 2,45 & 8.294 & 2,56 & 6,65 \\
5 a 14 anos & 1.892 & 7,85 & 26.933 & 8,29 & 6,56 \\
15 a 24 anos & 5.181 & 21,49 & 82.098 & 25,27 & 5,94 \\
25 a 34 anos & 5.996 & 24,87 & 81.470 & 25,08 & 6,86 \\
35 a 59 anos & 6.483 & 26,89 & 78.716 & 24,23 & 7,61 \\
60 anos e mais & 2.282 & 9,47 & 21.549 & 6,63 & 9,58 \\
Ignorada & 1.682 & 6,98 & 25.778 & 7,94 & 6,13 \\
Total & 24.107 & 100,00 & 324.838 & 100,00 & 6,91 \\
\hline
\end{tabular}

Tabela 2

Vítimas fatais e não fatais em acidentes de trânsito nas capitais brasileiras, para o ano de 1997 (Brasil, 1999a)

\begin{tabular}{lrrrrc}
\hline Faixa etária & \multicolumn{2}{c}{ Vítimas fatais } & \multicolumn{2}{c}{ Vítimas não fatais } & Letalidade \\
& \multicolumn{1}{c}{$\mathrm{n}$} & \multicolumn{1}{c}{$\%$} & $\mathrm{n}$ & $\%$ & $\%$ \\
\hline 0 a 4 anos & 144 & 2,28 & 2.990 & 2,40 & 4,59 \\
5 a 14 anos & 489 & 7,74 & 10.127 & 8,13 & 4,61 \\
15 a 24 anos & 1.256 & 19,89 & 30.309 & 24,34 & 3,98 \\
25 a 34 anos & 1.410 & 22,33 & 30.070 & 24,15 & 4,48 \\
35 a 59 anos & 1.705 & 27,00 & 29.855 & 23,98 & 5,40 \\
60 anos e mais & 692 & 10,96 & 8.049 & 6,46 & 4,92 \\
Ignorada & 619 & 9,80 & 13.119 & 10,54 & 4,83 \\
Total & 6.315 & 100,00 & 124.519 & 100,00 & \\
\hline
\end{tabular}

dos problemas já mencionados, tais estatísticas ainda apresentam um percentual significativo de vítimas para o qual a idade é desconhecida.

A Tabela 1 apresenta os dados sobre vítimas fatais e não fatais ocorridas em todo o território nacional em 1997 (Brasil, 1999a): 2,45\% das vítimas fatais tinham entre 0 e 4 anos de idade e $7,85 \%$ entre 5 e 14 anos, enquanto $2,56 \%$ das vítimas não fatais tinham entre 0 e 4 anos de idade e $8,29 \%$ entre 5 e 14 anos. A letalidade dos acidentados com menos de 15 anos é de 6,58\%, comparada com a de 6,91\% para os de todas as idades.

A situação das capitais brasileiras (Tabela 2) é a seguinte: $2,28 \%$ das vítimas fatais tinham entre 0 e 4 anos de idade e 7,74\% entre 5 e 14 anos, enquanto $2,40 \%$ das vítimas não fatais tinham entre 0 e 4 anos de idade e $8,13 \%$ entre 5 e 14 anos. A letalidade dos acidentados com menos de 15 anos é de 4,60\%, comparada com a de $4,83 \%$ para os de todas as idades.
Nas áreas urbanas ocorrem quase 70\% dos acidentes com vítimas, devido principalmente à alta concentração de atividades e de população: 209.151 acidentes na área urbana e 92.684 acidentes na área rural. Seria interessante comparar os indicadores de acidentes de trânsito nas áreas urbana e rural por faixa etária, no entanto só existem informações sobre o número de acidentes, agregados para todas as idades.

Se considerarmos que os percentuais da Tabela 2 podem dar um panorama do que acontece na área urbana do Brasil (o número de habitantes destas capitais varia desde 110.668 para a cidade de Palmas, até 9.927.868 para a cidade de São Paulo) pode-se deduzir que a letalidade dos acidentados nas áreas rurais deve ser maior que nas áreas urbanas, provavelmente pelas altas velocidades desenvolvidas nas estradas. Para as pessoas com menos de 15 anos, a letalidade é de 4,60\% nas capitais e $6,58 \%$ para todo o Brasil. Os esforços para pre- 
venir os acidentes e suas conseqüências devem ser os mesmos tanto nas áreas urbanas quanto nas rurais, no entanto, observando-se as características de cada uma: maior número de acidentados nas áreas urbanas e maior letalidade dos acidentados nas áreas rurais.

As mortes violentas de crianças e adolescentes incluem, além dos acidentes de trânsito, outras causas, como: afogamento, arma de fogo, arma branca, queimaduras, quedas, choque elétrico, estrangulamento e enforcamento. Segundo dados fornecidos pelo Instituto Médico Legal de 13 estados brasileiros (MA, GO, CE, AL, RR, PR, MG, MS, ES, RS, AM, PE e $\mathrm{SE}$ ), os acidentes de trânsito são a principal causa de mortes violentas de 0 a 14 anos de idade, sendo ultrapassados apenas pelas mortes por arma de fogo, para a faixa etária compreendida entre 15 e 18 anos (Brasil, 1993b). A Tabela 3 mostra os percentuais relativos aos atropelamentos e a outros tipos de acidentes de trânsito para as várias faixas etárias.

Os dados mais recentes da área da saúde sobre as mortes de pessoas de 0 a 19 anos (Brasil, 1998a) por acidentes de trânsito, para o país como um todo, são do ano de 1996: 6.832 óbitos, o que corresponde a $30,2 \%$ do total de óbitos por causas externas para este grupo etário. Os acidentes de trânsito lideram o ranking, seguidos por casos de agressão, com 6.170 registros. Estes dados ainda não foram desagregados por faixas etárias. Existem pesquisas mais atualizadas onde há a desagregação por faixa etária, mas apenas para algumas capitais brasileiras, como para a cidade do Rio de Janeiro (Tabelas 4 e 5).

A partir das declarações de óbitos de 1996, a Secretaria Municipal de Saúde do Rio de Janeiro (Rio de Janeiro, 1997) fez uma ampla pesquisa sobre as mortes por causas externas (Tabela 4). Os atropelamentos de crianças e adolescentes representaram $66,2 \%$ das causas de morte por acidentes de transporte. As crianças de 5 a 9 anos morreram mais por atropelamentos $(80,9 \%)$ que por outras causas de acidentes de transporte $(19,1 \%)$. Naquele ano, morreram 101 pessoas de 15 a 19 anos, quase a metade $(46,1 \%)$ de todas as vítimas fatais de 0 a 19 anos. Uma alta proporção desses acidentes ocorre no trajeto casa-escola. No Brasil, não foi realizada pesquisa que identificasse o percentual de acidentes no trajeto casa-escola. $\mathrm{Na}$ Inglaterra, este percentual ultrapassa os 25\% (Grayson, in Bradshaw, 1995).

Tabela 3

Proporção de mortes violentas por acidentes de trânsito em 13 estados brasileiros, no período 1991-1992 - 1o semestre de 1993 (Brasil, 1993b)

\begin{tabular}{lcccc}
\hline $\begin{array}{l}\text { Faixa etária } \\
\text { (anos) }\end{array}$ & $\begin{array}{c}\text { Atropelamento } \\
(\%)\end{array}$ & $\begin{array}{l}\text { Outros acidentes } \\
\text { de trânsito (\%) }\end{array}$ & $\begin{array}{l}\text { Outras causas } \\
\text { externas (\%) }\end{array}$ & Total (\%) \\
\hline 0 a 4 anos & 16 & 25 & 59 & 100 \\
5 a 11 anos & 28 & 34 & 38 & 100 \\
12 a 14 anos & 19 & 31 & 50 & 100 \\
15 a 18 anos & 9 & 26 & 65 & 100 \\
\hline
\end{tabular}

Tabela 4

Mortalidade proporcional por atropelamentos e por outros acidentes de transporte na cidade do Rio de Janeiro em 1996 (Rio de Janeiro, 1997)

\begin{tabular}{lcccc}
\hline Faixa etária & \multicolumn{2}{c}{ Atropelamentos } & \multicolumn{2}{c}{ Outros acidentes de transporte } \\
& $\mathrm{n}$ & $\%$ & $\mathrm{n}$ & $\%$ \\
\hline 0 a 4 anos & 18 & 64,3 & 10 & 35,7 \\
5 a 9 anos & 34 & 80,9 & 8 & 19,1 \\
9 a 14 anos & 32 & 66,7 & 16 & 33,3 \\
15 a 19 anos & 61 & 60,4 & 40 & 39,6 \\
+ de 20 anos & 746 & 65,3 & 397 & 34,7 \\
\hline
\end{tabular}


Tabela 5

Atendimentos do setor de emergência dos hospitais Miguel Couto e Salgado Filho por acidentes devidos a causas externas, durante os meses de maio e junho de 1996, respectivamente (Deslandes, 1997)

\begin{tabular}{lrrrrrrr}
\hline Evento & \multicolumn{4}{c}{ Faixa etária (anos) } & \multicolumn{3}{c}{ Total } \\
& $<1$ & $1-4$ & $5-9$ & $10-14$ & $15-19$ & \multicolumn{1}{c}{ n } & $\%$ \\
\hline Atropelamento & 0 & 2 & 15 & 23 & 35 & 75 & 4,3 \\
Ocupantes de carros de passeio & 0 & 4 & 5 & 10 & 35 & 54 & 3,1 \\
Passageiros de transporte público & 0 & 4 & 7 & 28 & 39 & 78 & 4,4 \\
Acidentes de trânsito (subtotal) & 0 & 10 & 27 & 61 & 109 & 207 & 11,8 \\
Outras causas externas & 35 & 309 & 284 & 407 & 506 & 1541 & 88,2 \\
Total & 35 & 319 & 311 & 468 & 615 & 1748 & 100,0 \\
\hline
\end{tabular}

Uma outra pesquisa sobre a morbidade e mortalidade na Cidade do Rio de Janeiro, foi realizada por Deslandes (1997), onde foi analisado quantitativamente o impacto da violência nos serviços de emergência em dois hospitais municipais do Rio de Janeiro: Hospital Municipal Miguel Couto e Hospital Municipal Salgado Filho, em maio e em junho de 1996, respectivamente, durante um mês, 24 horas por dia. Estes hospitais atenderam diariamente, em média, 15 vítimas da violência do trânsito, de todas as idades. A maioria dos acidentes deveu-se a atropelamentos. $\mathrm{Da} \mathrm{Ta}-$ bela 5 , verifica-se que das vítimas de acidentes de trânsito atendidas naqueles dois hospitais: a) quase $12 \%$ eram crianças e adolescentes, e b) do total de pessoas de 0 a 19 anos, 53\% tinham de 15 a 19 anos.

Na cidade do Rio de Janeiro, em 1996, Pinheiro et al. (1997) entrevistaram 739 crianças e adolescentes, de 9 a 17 anos, de quatro escolas da Zona Sul: duas públicas e duas privadas, de modo a investigar os reflexos da violência urbana. Os alunos, estimulados a definir o que é a violência, deram depoimentos muito expressivos, como por exemplo: "Violência é quando a gente não pode andar na rua”. Setenta e dois por cento e $64 \%$ dos alunos das escolas públicas e particulares, respectivamente, sofreram algum tipo de violência. A violência mais comum contra os entrevistados é o assalto: 56,6\% foram assaltados pelo menos uma vez desde que começaram a estudar. Segundo os autores, "nas escolas privadas, o sentimento dominante é a desesperança em relação a conviver com a violência, ao passo que na escola pública há mais inconformismo em ter sua mobilidade tolhida".

Analisando as informações contidas nas Tabelas 3, 4 e 5, é possível buscar explicações para a ocorrência destes tipos de acidentes, segundo a faixa etária. De 0 a 4 anos, presumese que os acidentes ocorram sobretudo quando estas crianças estão a bordo de veículos de passeio. No entanto, não é possível definir sem maiores informações, se os atropelamentos acontecem quando estão acompanhadas ou sós. Nos eventos deste último tipo (crianças não acompanhadas por adultos), é possível que as ocorrências se dêem também durante as brincadeiras nas ruas.

De 5 a 11 anos, elas continuam a se envolver em acidentes a bordo de veículos, mas a proporção de atropelamentos cresce. Nesta idade, muitos se utilizam de bicicletas; entretanto, não há informação se este tipo de acidente está incluído nos atropelamentos ou nos outros tipos de acidentes de trânsito. Provavelmente, várias viagens são feitas de forma autônoma, mas falta ainda conhecimento suficiente sobre a convivência com o trânsito, para permitir a travessia segura das vias. Este grupo começa a ingressar na escola, expondose ainda mais ao tráfego urbano no trajeto de e para a escola. Uma pesquisa realizada pelos autores deste artigo, ainda não publicada, em novembro de 1995, em quatro escolas públicas de primeiro grau na região suburbana do município do Rio de Janeiro, entrevistando 507 alunos e 174 pais, confirma o risco ao qual as crianças desta faixa etária são submetidas diariamente: $15 \%$ do total de alunos de 6 a 8 anos vão sozinhos à escola.

De 12 a 14 anos e, em seguida, de 15 a 18 anos, cai a proporção de mortes violentas por envolvimento em acidentes de trânsito, em comparação com outras causas. É bem provável que esta redução proporcional seja explicada pelo aumento da mortalidade por outras causas externas. É bom lembrar que alguns já 
começam a dirigir veículos, embora não estando habilitados para tanto. Pesquisa realizada na cidade de São Paulo, com 60 motoristas do sexo masculino, revelou que $63,3 \%$ deles haviam começado a dirigir antes de obter a Carteira Nacional de Habilitação. Em alguns casos, a experiência havia iniciado aos 12 anos de idade (Braga, 1989).

É possível que o risco para alguns destes grupos seja maior em função de algumas características, próprias dos jovens, que passam a contribuir para seu envolvimento em acidentes. Por um lado, estes não têm a mesma percepção que os adultos das situações de risco que caracterizam alguns comportamentos no trânsito.

Por outro lado, os jovens podem estar mais motivados a assumir comportamentos de risco na medida em que sentem necessidade de autonomia (contrapondo-se à autoridade dos pais e das normas sociais), necessidade de novidades e de sensações, bem como necessidade de auto afirmação, quando o risco caracteriza-se como uma fonte de prestígio e de competitividade. Existe ainda um fator complicador, o sexo, uma vez que o risco não tem o mesmo significado para homens e mulheres (Bajornet et al., 1992). É possível que este fato explique, em parte, o envolvimento diferenciado em acidentes de trânsito e outras mortes violentas, para jovens do sexo masculino e do sexo feminino.

A avaliação da situação existente permite apontar alguns encaminhamentos de um trabalho que tente minimizar o risco para crianças e adolescentes. Em primeiro lugar, é fundamental investir numa reorganização do trânsito e das áreas urbanas que proporcione uma relação mais harmoniosa entre a população que está sendo enfocada aqui, principalmente, e o ambiente de tráfego. Finalmente (e este ponto deve ser prioritário), há necessidade urgente de investir na educação para o trânsito e na prevenção dos atropelamentos, medidas que beneficiariam não apenas estas faixas etárias, mas todos os outros usuários.

\section{A reorganização do tráfego e das áreas urbanas}

É possível verificar uma desarmonia entre o tráfego urbano - tal como está estruturado atualmente na grande maioria das cidades brasileiras - e uma parcela altamente significati- va dos usuários, os pedestres e, particularmente, as crianças e os adolescentes. O planejamento, a operação e a fiscalização do tráfego devem ser concebidos levando-se em consideração as necessidades e especificidades de todos os tipos de usuários do sistema de tráfego. Historicamente, as ações voltadas para o tráfego não têm considerado, de forma balanceada, as demandas dos diferentes tipos de usuários. As medidas adotadas têm, sistematicamente, privilegiado o trânsito de veículos motorizados: o alto número de atropelamentos é um indicador desta situação. Esta prática obriga os pedestres a se adaptarem ao meio ambiente de tráfego e às situações criadas, onde freqüentemente estes usuários se encontram em desvantagem face aos motoristas e passageiros de veículos. As crianças e adolescentes transitando a pé são ainda mais prejudicados, tendo em vista as características comportamentais destes grupos, já mencionadas anteriormente.

É fundamental, portanto, reorganizar o tráfego e as áreas urbanas, de modo a se garantir os direitos do cidadão-pedestre e de se romper com as práticas que promovem a segregação e o isolamento de comunidades, tão prejudiciais ao convívio social e à movimentação a pé. Para tanto, é urgente rever a hierarquização do sistema viário nas zonas urbanizadas. As vias não possuem as mesmas características físicas, pertencem a áreas com usos do solo e densidades de ocupação distintas e, portanto, com movimentação diferenciada de veículos e de pessoas. A hierarquia estabelecida para os componentes da rede viária deve levar em conta estas diferenças.

A função das vias é ligar partes da área urbana através de rotas eficientes (no que diz respeito ao escoamento do fluxo de veículos e de pedestres) e seguras (IHT, 1990). Mas é também permitir acesso a atividades lindeiras, possibilitar o estacionamento de veículos e ainda propiciar um ambiente para lazer e convivência social. Isto só é possível se o fluxo de tráfego em cada via e o desempenho de cada uma delas forem compatíveis com as funções esperadas, a partir da hierarquização estabelecida para a rede viária em questão. A definição clara das funções e tipos de vias deve promover um equilíbrio entre a sua capacidade de tráfego, o meio ambiente local, as velocidades desenvolvidas pelos veículos, as condições de segurança e de conforto dos usuários (IHT, 1989). 
Quando a via não consegue acomodar, em condições de equilíbrio, demandas e usos conflituosos, é urgente uma restruturação que estabeleça, na prática, o papel que a via desempenha dentro da rede, para qual de suas finalidades dever ser dada prioridade e qual a relação existente com outras vias da mesma área.

Este tipo de intervenção também é uma maneira de utilizar o espaço viário como uma ferramenta, um mecanismo para viabilizar a existência de áreas ambientais, fazendo distinção entre vias com função predominante de escoamento do tráfego e outras que podem abrigar o acesso às edificações, o deslocamento de pedestres e ciclistas, atividades individuais e comunitárias.

É fundamental ressaltar que deve-se considerar também os ganhos mais gerais em qualidade de vida, além do aspecto segurança, que medidas como a hierarquização viária podem trazer. Ao tratar de uma reorganização das áreas urbanas, dentro de uma perspectiva de minimização do risco para crianças e adolescentes, deve-se avaliar os impactos ambientais aceitáveis, ao determinar o tráfego máximo de veículos (de diferentes tipos) que a área em questão pode suportar. Para tanto, deve-se estabelecer a capacidade da via ou área para acomodar veículos em movimento ou estacionários, considerando a necessidade de se manter padrões ambientais pré-estabelecidos (para ruído, poluição atmosférica, etc.). Esta capacidade, dita ambiental, pode ser inferior à capacidade de tráfego da via (HMSO, 1963) e deveria ser vista como um limite não menos importante que a capacidade de tráfego.

A insegurança no trânsito para crianças e adolescentes está relacionada também com o urbanismo, ou seja, com a forma como as cidades são planejadas e construídas. Os administradores não levam em conta as características e o olhar das crianças e dos adolescentes. A maioria das cidades, enquanto espaço público, apenas atende às necessidades de lazer deste público, através da construção de praças. No entanto, eles também precisam andar nas ruas com segurança.

A percepção que o cidadão tem do meio ambiente de tráfego vai influenciar seu comportamento no trânsito e seu relacionamento com os outros usuários (Braga, 1989). As informações das quais se dispõe indicam uma relação de conflito entre os diversos usuários do sistema de tráfego que se traduz, em parte, em acidentes. "A imagem de um bom ambien- te dá, a quem a possui, um sentido importante de segurança emocional. Pode estabelecer uma relação harmoniosa entre si e o mundo exterior" (Lynch, 1960). Para mudar a relação (atual) das pessoas, em especial das crianças e adolescentes, com o tráfego urbano, é de grande importância promover uma harmonia entre o cidadão e o meio ambiente de tráfego.

\section{Prevenção dos atropelamentos}

O segundo elenco de medidas recomendadas neste trabalho diz respeito a tratamentos voltados para a prevenção dos atropelamentos, principal problema no caso das crianças e dos adolescentes. Algumas medidas são direcionadas especificamente para este grupos e outras beneficiam todos os usuários das vias públicas. Na sua maioria, são medidas de engenharia de tráfego, mas também utilizam, em alguns casos, enfoques de educação, fiscalização, urbanismo e paisagismo.

\section{Sistema de informações}

Como determina o Código de Trânsito Brasileiro (CTB), é competência do Denatran a gerência das informações sobre acidentes de trânsito. Ele deve definir um novo modelo de Boletim de Ocorrências de Acidentes de Trânsito (Boat), em substituição ao Brat, que inclua uma série de informações relevantes para o diagnóstico da situação existente no local do acidente e para o estudo e o tratamento de áreas e pontos críticos, trechos de vias e cruzamentos, sem perder de vista os aspectos legais e jurídicos dos acidentes de trânsito: a identificação do acidente; as condições presentes no momento da ocorrência e os fatores contribuintes; os dados sobre o tipo de acidente; os veículos e as pessoas envolvidas; o croqui do acidente; e as descrições adicionais que porventura se fizerem necessárias.

A partir do Boat, o Denatran deve implantar um sistema de coleta e tratamento de informações, definindo assim todos os dados a serem coletados pelos demais componentes do Sistema Nacional de Trânsito: cadastro viário, fluxo de veículos, registro de acidentes de trânsito, etc. 


\section{Verificação das rotas de circulação de pedestres e dos principais pontos de travessia}

É comum verificar que os órgãos gestores do trânsito das cidades brasileiras sinalizam os locais para a travessia das vias sem um estudo das rotas de circulação de pedestres, não atendendo, assim, às necessidades dos pedestres, que continuam arriscando-se no trânsito.

A metodologia desenvolvida na década de 60 por Fruin (1970) para identificar "linhas de desejo" de pedestres e os critérios propostos para o projeto de implantação de infra-estrutura para pedestres, ainda é aplicável nos dias de hoje e deve ser utilizada quando se pretende elaborar um programa de ação para melhorar a segurança de crianças e adolescentes.

\section{Revisão dos semáforos}

No Brasil, os semáforos padecem de uma completa falta de padronização, com diversos símbolos para indicar o direito de passagem do pedestre nas travessias, alguns ininteligíveis e outros conflitantes. A adoção de uma mesma simbologia nos focos semafóricos dos pedestres vai beneficiar principalmente as crianças, face às suas limitações naturais de apreender símbolos e de representação da realidade.

Os tempos destinados aos pedestres nas travessias semaforizadas, quase sempre, são dimensionados sem levar em conta as características das crianças e dos adolescentes: seu tempo de percepção e reação, que é maior do que o de um adulto, e sua velocidade, que é menor do que de uma pessoa adulta. Assim, nem sempre há tempo suficiente para garantir uma travessia segura a estes usuários, que precisam correr para conseguir completar a travessia.

A manutenção inadequada da sinalização de trânsito é mais perigosa do que a sua falta, pois qualquer sinalização induz o usuário a acreditar em suas indicações. No Brasil, os semáforos, principalmente os de pedestre, não recebem uma manutenção adequada. Os órgãos gestores do trânsito, quando o fazem, priorizam a manutenção dos blocos semafóricos veiculares nas interseções. Se os pedestres sempre obedecessem às indicações semafóricas, sem antes verificar seu funcionamento, o número de atropelamentos poderia ser bem maior do que o atual.

\section{Ação educativa junto a travessias de pedestres}

Uma das experiências atuais mais bem sucedidas de aluno-guia ou patrulha escolar ocorreu no início dos anos 90, na cidade de Joinville, que realizou um amplo programa de educação, engenharia e segurança no trânsito. Juntamente com ampla campanha educativa em diversas formas de mídia e com a sinalização e a implantação de obras de engenharia nas portas das escolas públicas e particulares, da pré-escola à oitava série do primeiro grau, alguns de seus alunos foram treinados pela Polícia Militar, para orientar a travessia das ruas em frente às escolas. Além de motivar as crianças e os adolescentes sobre a questão da segurança no trânsito, este programa conseguiu, no primeiro ano de sua aplicação, uma redução de 59,2\% no número de mortes (Piske, 1991). Esta experiência deve ser reavaliada para os dias atuais, mas se envolver a participação da comunidade e ações de educação, engenharia e esforço legal, tem amplas possibilidades educativas e de redução dos atropelamentos de crianças e adolescentes.

Mesmo nos locais onde não se consiga implementar programas de educação do tipo aluno-guia, os pedestres e, particularmente, as crianças e os adolescentes, devem ser orientados por agentes de trânsito ou por professores e pais de alunos, preparados para esta tarefa, sobre como se comportar no trânsito, utilizando a persuasão e outros métodos mais justos e eficazes para garantir sua obediência. Algumas cidades como São Paulo, Belo Horizonte e Niterói já têm utilizado agentes contratados para esta tarefa, sobretudo nas áreas centrais.

\section{Tratamento de travessias}

A ocupação irracional do espaço urbano e as deficiências da infra-estrutura de transportes geram inúmeros conflitos entre veículos e pedestres que são acentuados pelo despreparo destes usuários, com nítida desvantagem para os pedestres. As metodologias utilizadas pelos técnicos brasileiros para sinalizar os locais de travessia de pedestres são derivadas de condições diferentes da nossa realidade. Assim, sem fazer os ajustes necessários às especificidades locais ou, então, usando critérios subjetivos sem fundamentos técnicos que os justifiquem plenamente, têm sido implantadas travessias inadequadas e inseguras. 
O tratamento correto dos locais de travessia, aliado a campanhas educativas, pode efetivamente reduzir os atropelamentos. O Manual de Segurança de Pedestres do Denatran (Brasil, 1979) dá boas indicações e orientações sobre alguns tratamentos de travessias de pedestres.

Uma outra fonte de informação, orientação e treinamento para os técnicos dos órgãos de trânsito foi desenvolvida por Faria (1994), que elaborou o Sistema Especialista para o Tratamento de Travessias de Pedestres segundo uma metodologia que auxilia na decisão sobre a real necessidade e o tipo mais apropriado de tratamento a ser implantado nas travessias exclusivas de pedestres.

\section{Tratamento de pontos críticos}

Tradicionalmente, os atropelamentos têm sido abordados dentro do tratamento de pontos críticos, locais da área urbana onde se concentra a ocorrência de acidentes de trânsito. Também podem ser objeto de estudo em estratégias que enfocam especificamente um determinado tipo de deficiência (por exemplo, equipamentos em travessias de pedestres) ou determinado tipo de acidente (atropelamentos, por exemplo).

Todas estas estratégias têm por base informações sobre a concentração destes acidentes nas áreas urbanas, os horários nos quais eles ocorrem com menor freqüência, a variação em função dos dias da semana ou dos meses do ano e ainda que tipo de usuário está mais sujeito ao envolvimento em atropelamentos.

Os órgãos gerenciadores de trânsito, principalmente os das administrações municipais que recentemente passaram a atuar no trânsito, a partir do CTB, podem utilizar o Sistema Especialista para Diagnose e Tratamento de Interseções Urbanas Críticas (Faria \& Vieira, 1994) que visa a orientar os usuários no diagnóstico e tratamento de interseções urbanas identificadas como perigosas, através de medidas corretivas que minimizem a gravidade e a quantidade dos acidentes de trânsito.

É comum em outros países que os acidentes envolvendo usuários mais vulneráveis (pedestres e ciclistas) não se concentrem nos chamados pontos críticos (IHT, 1990). Se este for o caso também do Brasil, a alternativa de se utilizar outras estratégias trará benefícios para estes usuários, uma vez que os locais de risco, sobretudo de atropelamento, podem estar mais distribuídos na rede viária.
De fato, tem crescido em importância, em países como aqueles do Reino Unido, a estratégia de tratamento por área (substituindo a relevância dada, no passado, a abordagens voltadas para pontos específicos da rede viária urbana). Neste enfoque, uma área que congrega um conjunto de vias de características semelhantes é tratada como um todo, levandose em conta todos os fatores possíveis de afetar a segurança do tráfego e tendo como base a hierarquização viária para a escolha destes locais (IHT, 1990). Nesses casos, situações semelhantes recebem tratamentos idênticos, mesmo que as estatísticas de acidentes não sejam iguais. Entretanto, a segurança não é o objetivo único deste tipo de abordagem: sua amplitude visa a promover um equilíbrio entre o uso do solo local, o meio ambiente, a fluidez do tráfego e as condições de segurança. Os benefícios advindos são, portanto, de melhoria da qualidade de vida.

\section{Melhoria dos passeios}

A maioria dos passeios públicos nas vias dos centros urbanos apresenta características que dificultam e tornam insegura a circulação de pedestres: largura insuficiente, pisos escorregadios e em mau estado de conservação, desníveis abruptos, ausência de facilidades para deficientes físicos, má instalação de equipamentos urbanos, presença de elementos decorativos, vendedores ambulantes, carros estacionados, bancas de jornais desproporcionais e muitos outros elementos que contribuem para a redução da capacidade ou para tornarem problemáticos os deslocamentos de pedestres nas calçadas.

Assim, um projeto de infra-estrutura para pedestres, a melhoria do nível de serviço e das condições de manutenção e a fiscalização do uso das calçadas podem contribuir para a redução dos atropelamentos de crianças e adolescentes.

Existem diversas metodologias para análise e projeto de passeios [ITE (1982), TRB (1985), Abishai (1993)] que podem ser utilizadas. Faria et al. (1993) propõem uma sistemática para analisar a circulação de pedestres nos passeios dos centros comerciais urbanos, que pode ser bastante útil como uma ferramenta para o poder público e para a comunidade, na discussão sobre a ocupação do espaço urbano, indicando parâmetros racionais para a negociação entre os agentes envolvidos na questão. 


\section{Fiscalização e controle}

A redução no número de mortos e feridos no trânsito conseguida com o anúncio da entrada em vigor do CTB demonstrou a forte influência do esforço legal na segurança de trânsito. Todas as regras de circulação, estacionamento e parada contidas no CTB devem ser fiscalizadas; no entanto, para reduzir os atropelamentos de pedestres crianças e adolescentes, algumas merecem ser fiscalizadas com mais intensidade: estacionamento sobre calçadas, avanço de sinais, excesso de velocidade e consumo de bebida alcoólica.

\section{Atendimento aos acidentados}

As chances de vida e de redução no grau das seqüelas aumentam com a presteza e a qualidade destes serviços. Neste sentido, as rodovias brasileiras deveriam ser dotadas de serviços de atendimento de emergência, oficiais ou particulares, assim como o Corpo de Bombeiros, deveria ser melhor aparelhado para o atendimento aos acidentados.

\section{Educação para o trânsito nas escolas}

Estudos internacionais comprovam que os programas de redução dos acidentes de trânsito mais eficazes são aqueles que propõem ações conjuntas de educação, de engenharia e de esforço legal (OCDE, 1986). Estes estudos ressaltam que é fundamental investir em educação, mesmo que seus resultados sejam de complexa monitoração ou que devam ser esperados, pelo menos, a médio prazo.

A educação para o trânsito, e especialmente a do público infanto-juvenil, é um dos instrumentos que podem contribuir para a redução a médio e a longo prazos dos índices alarmantes de acidentes no trânsito, pois um trânsito efetivamente seguro só será conseguido quando os cidadãos forem mais conscientes de sua responsabilidade individual e mais respeitadores dos direitos dos outros. A sociedade pode conseguir mais facilmente que seus cidadãos desenvolvam estes valores se, desde cedo, as crianças e os adolescentes forem educados, para que, quando adultos, tornem-se pedestres e, principalmente, motoristas mais conscientes.

\section{A experiência brasileira na educação para o trânsito}

Nos últimos anos, alguns setores da sociedade brasileira têm se esforçado para resgatar a importância de se educar crianças para o trânsito urbano.

Apesar do Conselho Federal de Educação ter estabelecido a portaria 678/91, que determinou a difusão de temas e conteúdos específicos da educação para o trânsito na grade curricular das escolas para alunos de 7 a 18 anos, poucas cidades (Belo Horizonte, Vitória, Florianópolis, Goiânia, Campinas, Santos, Campo Grande, São Paulo, Curitiba, Joinville e Canoas) seguiram esta orientação, que consiste na abordagem da educação para o trânsito em todas as disciplinas afins.

O Programa Volvo, que foi encerrado sem justificativas em 1996, reunia especialistas de todo o Brasil e do exterior para discutir e propor medidas para fomentar a educação para o trânsito.

O CTB (Brasil, 1997), que tem um capítulo específico sobre educação para o trânsito, torna obrigatório em todo o território nacional o ensino desta matéria nas escolas particulares e públicas, em todos os níveis. Estas tentativas são bastante recentes, mas pode-se estimar que, no Brasil, nem 10\% dos alunos das escolas brasileiras têm acesso às informações sobre educação para o trânsito.

Atualmente, no Brasil, existem dois tipos de abordagens em relação à educação para o trânsito. Algumas cidades a consideram como uma disciplina específica, outras adotam o conceito de interdisciplinaridade, ou seja, o tema da educação para o trânsito não constitui uma nova matéria escolar; ele é abordado em todas as disciplinas.

A prática brasileira na educação para o trânsito é falha por diversos motivos:

- fundamenta-se na experiência estrangeira que, principalmente, ensina como se "safar dos perigos do trânsito", sem estudos necessários para sua adaptação à nossa realidade; - a maioria das escolas aborda o tema trânsito apenas no seu aspecto cognitivo, não atendendo desta forma, às suas peculiaridades, que exigem uma sensibilização quanto aos seus aspectos éticos, à importância da cooperação no trânsito, ao respeito aos direitos dos outros, etc.;

- acredita-se que o ensino das regras de trânsito e das conseqüências legais da sua inobser- 
vância sejam suficientes para modelar o comportamento dos alunos, quando forem futuros motoristas;

- as abordagens pedagógicas utilizadas nesta área são desenvolvidas de acordo com uma concepção tradicional onde os técnicos/adultos identificam os conceitos e os aspectos do tema, bem como produzem os instrumentos necessários para tanto. Alguns manuais de educação para o trânsito, como o da prefeitura de Joinville (Joinville, 1990), consideram importante que uma criança da 6a série, com 11 ou 12 anos, classifique os veículos quanto à espécie e categoria (oficial, particular, diplomático, etc.) ou que um adolescente da 8 a série, com 13 ou 14 anos, saiba quais as funções dos órgãos normativos e executivos de trânsito;

- por esta concepção, o ponto de vista, a percepção e a expectativa do público a atingir não são pesquisados, nem tampouco levados em consideração e o tema é abordado somente de forma cognitiva, o que nem sempre resulta na adoção de comportamentos adequados no trânsito ou na mudança de comportamento; - o ensino da educação para o trânsito também sofre reflexos da situação da educação em geral, onde muitas crianças ainda não têm acesso à escola: baixa remuneração, falta de incentivo e de reciclagem dos professores; ausência de material e instalações satisfatórias.

O currículo interdisciplinar nacional para a educação para o trânsito, a ser elaborado pelo Contran e pelo MEC, deverá consolidar esta falha prática brasileira, com suas metodologias pedagógicas e conteúdos. As possibilidades de insucesso do ensino de educação para o trânsito, como está proposto no CTB, são grandes, pelos motivos expostos anteriormente e também porque o ensino tradicional adotado na maioria das escolas brasileiras fragmenta os conteúdos em disciplinas e em especialidades, enquanto a proposta do MEC e do Denatran não é fragmentada. Nesta proposta, não existe a figura de um professor que faça a "costura" dos conteúdos dispersos pela grade curricular.

\section{Proposta de educação para o trânsito}

Entre 1996 e 1998, os autores entrevistaram mais de 40 especialistas em todo o Brasil (Faria \& Braga, 1999), que definiram quais deveriam ser os principais objetivos da educação para o trânsito e quais as condições necessárias para o sucesso de programas de educação para o trânsito. Entre outras, pode-se citar:
- atuação do poder público, em todos níveis, reduzindo os conflitos na disputa pelo espaço viário e reduzindo o tempo de exposição ao risco, garantindo sua continuidade de uma administração para outra;

- coordenação adequada das ações privadas ou oficiais;

- melhoraria das condições da infra-estrutura viária e da operação do tráfego, principalmente junto às escolas;

- participação intensa da iniciativa privada e da comunidade;

- planejamento levando em conta o nível de conhecimento do público alvo e monitoração durante e após sua execução.

Não é possível mudar comportamentos no trânsito abordando o tema como tem sido feito no Brasil. O tema precisa ser inserido num contexto mais amplo, onde a criança e o adolescente possam refletir sobre os aspectos éticos do comportamento no trânsito, para assim entender os motivos das regras de trânsito (a segurança para todas as pessoas) e adotar comportamentos humanos no trânsito.

O tema trânsito pode ser abordado no ensino de ética, que está proposto no documento "Parâmetros Curriculares Nacionais" do Ministério da Educação e do Desporto (Brasil, 1998b) como um tema transversal. Assim, o professor de ética, se treinado para isso, poderá assumir o papel de fazer a ligação entre os diferentes conteúdos transmitidos nas diversas disciplinas que farão parte do currículo interdisciplinar sugerido pelo CTB.

Em síntese, um programa de educação para o trânsito, que transforme o estudante em um agente ativo no processo ensino/aprendizagem e que contribua para a adoção de comportamentos humanos no trânsito e para a mudança de comportamentos de risco, deverá ter como meta contribuir para o processo de formação de cidadãos conscientes de sua responsabilidade individual e respeitadores dos direitos dos outros. Deve também desenvolver o tema de uma maneira abrangente nos seus diferentes aspectos (histórico, social, local, legal, comunitário, etc.), de forma a favorecer a compreensão do aluno de sua realidade local e da relação desta com o conjunto da sociedade. Só assim, um programa educativo tem condições de promover de modo mais efetivo a adoção de comportamentos adequados e a mudança de comportamento de risco dos usuários dos sistemas de transporte. 


\section{Conclusões e proposições}

A amputação da cidadania e da solidariedade social através de um modelo político, o incentivo ao individualismo através de um modelo econômico que tornou os indivíduos mais consumidores do que cidadãos e a alienação provocada por um processo de fragmentação do homem e do conhecimento, fizeram com que o país chegasse a uma profunda crise de valores onde o respeito ao indivíduo não tem espaço e onde a vida vale muito pouco. Os acidentes de trânsito são um reflexo desta crise de valores e se transformaram num dos mais graves problemas que a população brasileira enfrenta nos seus deslocamentos, principalmente para as crianças e adolescentes.

Qualquer programa de redução de acidentes deveria seguir três etapas fundamentais: a) conhecimento do problema, através de dados e informações, incluindo uma reflexão sobre os aspectos relacionados com a estrutura política e social; b) definição dos objetivos prioritários a alcançar; e c) escolha das medidas mais apropriadas para tratar do problema, que não se restrinjam à abordagem da engenharia de tráfego, mas também da fiscalização e da educação para o trânsito e do urbanismo.

Neste texto, procurou-se analisar a segurança de crianças e adolescentes, com base nas informações limitadas que se dispõe e na experiência com relação à prevenção dos tipos de acidentes aos quais este grupo de usuários está mais sujeito. A avaliação da situação existente permitiu apontar alguns encaminhamentos de um trabalho que tente minimizar o risco para crianças e adolescentes: a) é necessário e urgente investir numa reorganização do trânsito e das áreas urbanas, na prevenção dos atropelamentos e na educação pa- ra o trânsito; b) é fundamental reorganizar o tráfego e as áreas urbanas, de modo a garantir os direitos do cidadão-pedestre (segurança e qualidade de vida), através da hierarquização do sistema viário, efetivada principalmente por intervenções físicas. A reorganização das áreas urbanas deve levar em conta as características e o olhar das crianças e dos adolescentes. Eles não desejam apenas locais para lazer, mas também precisam andar nas ruas com segurança.

Como os atropelamentos são o principal problema para crianças e adolescentes, foram propostas medidas voltadas para a sua prevenção: implantação de um sistema de informações sobre acidentes de trânsito; verificação das rotas de circulação de pedestres e dos principais pontos de travessia; revisão dos semáforos; tratamento e ação educativa junto às travessias de pedestres; tratamento de pontos críticos; melhoria dos passeios; ampliação e melhoria da fiscalização de trânsito e do atendimento aos acidentados.

A educação para o trânsito, e especialmente a do público infanto-juvenil, é também um instrumento que pode contribuir para a redução dos acidentes de trânsito, a médio e a longo prazos, através da mudança de comportamentos de risco e do desenvolvimento de comportamentos adequados, da consciência da responsabilidade individual e do respeito aos direitos dos outros. A sociedade pode conseguir mais facilmente que seus cidadãos desenvolvam estes valores se, desde cedo, as crianças e os adolescentes forem educados, para que, quando adultos, tornem-se pedestres e, principalmente, motoristas mais conscientes. Neste trabalho, também, foram propostos os fundamentos que devem nortear os programas de educação para o trânsito.

\section{Referências}

Abishai P 1993. Pedestrian flow and level of service. Journal of Transportation Engineering 109(1).

Bajornet P-E, Lagarde D, Serveille J 1992. Sécurité Routière. Presses de l'École Nationale des Ponts et Chaussées, Paris.

Bradshaw R 1995. Why do parents drive their children to school? Traffic Engineering + Control: 16-19.

Braga MGC 1989. The Vehicle Drivers' Perception of Attributes of the Road Environment that Influence Safety of Four-arm Uncontrolled Junctions. Tese de Doutorado, Imperial College of Science, Technology and Medicine, London. 
Braga MGC 1992. Acidentes de trânsito no Brasil: agressão quotidiana ao meio-ambiente urbano. Revista de Administração Pública - RAP 2/95, Fundação Getúlio Vargas, Rio de Janeiro.

Brasil 1979. Manual de Segurança de Pedestres. Departamento Nacional de Trânsito, Ministério da Justiça, Brasília.

Brasil 1993a. Estatuto da Criança e do Adolescente. Centro Brasileiro para a Infância e Adolescência. Ministério do Bem-Estar Social, Brasília.

Brasil 1993b. Violência Contra a Criança e o Adolescente: Proposta Preliminar de Prevenção e Assistência à Violência Doméstica. Ministério da Saúde, Secretaria de Assistência à Saúde, Departamento de Assistência e Promoção à Saúde, Coordenação Materno-Infantil. Serviço de Assistência à Saúde do Adolescente, Brasília.

Brasil 1997. Código Brasileiro de Trânsito. Ministério da Justiça, Brasília.

Brasil 1998a. Mortalidade no Brasil, 1996. Ministério da Saúde, Fundação Nacional de Saúde, Cenepi, Sistema de Informações sobre Mortalidade, Brasília.

Brasil 1998b. Parâmetros Curriculares Nacionais. Ministério da Educação e Cultura, Brasília.

Brasil 1999a. Informe Estatístico - 1997. Ministério da Justiça, Sistema Nacional de Trânsito, Brasília.

Brasil 1999b. Anuário Estatístico - 1998. Geipot, Departamento Nacional de Trânsito, Ministério dos Transportes, Brasília.

Deslandes SF 1997. O Impacto da Violência nos Serviços de Emergência Hospitalar: Relatório Final de Pesquisa. Claves/ENSP/Fiocruz, Rio de Janeiro.

Faria EO 1994. Sistema Especialista para Tratamento de Travessias de Pedestres. Dissertação de Mestrado. Coordenação dos Programas de Pós-graduação de Engenharia, Universidade Federal do Rio de Janeiro, Rio de Janeiro, $162 \mathrm{pp}$.

Faria EO \& Braga MGC 1999. Educando Crianças para o Trânsito Urbano com o Computador: uma Proposta de Software Educativo. Transporte em Transformação II: trabalhos vencedores do Prêmio CNT Produção Acadêmica 1997, p. 1-19. Markron Books \& Confederação Nacional do Transporte, São Paulo.

Faria EO \& Vieira A 1994. Sistema Especialista para Diagnose e Tratamento de Interseções Urbanas Críticas: Relatório Final. Programa de Engenharia de Transportes, Coordenação dos Programas de Pós-graduação de Engenharia, Universidade Federal do Rio de Janeiro, Rio de Janeiro.
Faria EO, Dalto EJ, Mesquita JMB \& Guerra RD 1993. Sistemática para analisar a circulação de pedestres nos passeios dos centros comerciais urbanos, p. 769782. VII Congresso da Associação Nacional de Pesquisa e Ensino em Transportes, v. 2, São Paulo.

Fruin JJ 1970. Designing for Pedestrians: a Level of Service Concept. Tese de Doutorado, Polytechinic Institute of Brooklin, Brooklin.

HMSO 1963. Traffic in Towns: a Study of the Long Term Problems of Traffic in Urban Areas, London.

IHT 1989. Roads and Traffic in Urban Areas. The Institution of Highways and Transportation, HMSO, London.

IHT 1990. Guidelines on Urban Safety Management. The Institution of Highways and Transportation, London.

ITE 1992. Traffic Engineering Handbook. Institute of Transportation Engineers, New Jersey, EUA.

Joinville 1990. Educação para o Trânsito: Subsídios para $5 \underline{a}$ a 8 a Série do 1o Grau. Comissão Comunitária para Humanização do Trânsito, Governo do município de Joinville, $51 \mathrm{pp}$.

Lynch K 1960. A Imagem da Cidade. Edições 70, Lisboa.

OCDE 1986. Efficacité des Programmes d'Education à la Sécurité Routière. Organisation de Coopération et Dévelopmment Économiques, Recherche Routière, Paris.

Pinheiro P et al. 1997. A Violência Urbana e seus Reflexos na Criança e Adolescente. XXX Congresso Brasileiro de Pediatria, Rio de Janeiro.

Piske O 1991. Educação de Trânsito nas Escolas - o Exemplo de Joinville. Simpósio Nacional Volvo de Segurança no Trânsito, p.10-11. Programa Volvo de Segurança no Trânsito, São Paulo.

Rio de Janeiro 1997. Mortes por Causas Externas na Cidade do Rio de Janeiro no Ano de 1996.: Relatório de trabalho No. 7. Superintendência de Saúde Coletiva, Coordenação de Programas de Epidemiologia, Gerência de Informação Epidemiológica, Secretaria Municipal de Saúde, Rio de Janeiro.

TRB 1985. Highway Capacity Manual. Transportation Research Board, Washington, EUA. 